\title{
An Attempt to Explore and Study the Inter-relationships amongst the various Clinic Metrics for Measuring the Performance of Physiotherapy Clinics and Health Care Centres
}

\author{
Ravdeep Singh \\ Jaslok Physiotherapy \\ Centre \\ Delhi, India
}

\author{
Remica Aggarwal \\ Recventure Education \\ Services Private Limited \\ Delhi, India
}

\author{
Veena Aggarwal \\ Recventures Education \\ Services Private Limited, \\ Delhi, India
}

\author{
Lokik Aggarwal \\ Recventures Education \\ Services Private Limited, \\ Delhi, India
}

\begin{abstract}
Owning a clinic is more than a full time job . Not only the owner has to work towards providing treatments to the patients but also they are required to spend quality time doing management stuff as well. However, the latter is superseding the former nowadays. Therefore, it is important to have a solid business plan and be looking at the right metrics so that the clinic owners makes sure that they are moving the business in the right direction or wrong direction. Yet, when it comes to metrics, most clinic owners aren't looking at the right things, that's if they are even looking at their metrics at all . Present research paper therefore focuses on exploring the various performance metrics and indicators for measuring the performance of Physiotherapy clinics and health care organizations . Thereafter, it studies the inter-relationship amongst the various physiotherapy metrics (as a demonstration) using ISM methodology . The research work concludes with the necessary managerial implications and recommendations.
\end{abstract}

\section{Keywords}

Physical therapy; Physiotherapy; ISM Methodology

\section{INTRODUCTION}

Physical therapy or physiotherapy emphasizes more than world-class patient care ${ }^{1}$. Therapists are also focused on doing good business. One way physical therapists and / or physiotherapy clinic owners maintain strong businesses is by paying close attention to clinic metrics. Clinic metrics are figures used to measure the efforts of your physical therapy practice. You can use these metrics to create targets for goal achievement or to modify current practices and improving clinic's performance. When it comes to metrics, the most obvious thing that comes to a person's mind is the revenue generation and number of new patients or patients visits. The truth is that while we do need to track them, they aren't leading metrics. Instead, when looking at metrics, it's very important to measure the month over month trends (February vs January) or year over year trends (January this year vs January last year) or the weekly trends .

Practically such metrics are developed with the involvement of physical therapists with the complete understanding of the various processes such as referrals processes, quality improvement processes or productivity related processes or the development of rehabilitation-specific QIs ; collection and development, analysis and reporting of related data collected 1,2 .
The process involves defining target audience ; determining the clinical area to evaluate; identifying existing processes and data; development of metrics based on the existing and newly collected data etc. The decision about the clinical area is based on a number of factors, including regulatory requirements, payer demands, public concerns, and importance of the health care issue. Other important considerations include whether there are opportunities to change clinical practice and improve quality of care and patient outcomes within the clinical area etc.

Health care is one of the fastest growing sector in India and has made substantial progress, especially in the last decade. Between 2000 and 2014, there was a 370\% increase in health expenditure. Historically, health care delivery in independent India has been under the purview of government. Indian government is striving hard to provide world class and affordable health services to its citizens . On the policy side, Indian government has made a bold commitment to achieve universal health coverage through Ayushman Bharat (AB) which aims to provide affordable health care to entire population and reduce expenses on health care . To improve care for their citizens and to realize these potential efficiency gains, policymakers are looking for methods to measure and benchmark the performance of their health care systems as a precondition for evidence-based health policy reforms. Health care metrics if appropriately evaluated would allow better organization and management of medical care and help the corresponding state to spend their health budget more prudently.

The next section explores the various metrics for physiotherapy clinics and health centers . Thereafter, section 3 provides the managerial implications and recommendations and section 4 the future directions.

\section{EXPLORATION OF VARIOUS METRICS FOR PHYSIOTHERAPY CLINICS / HEALTH CARE CENTERS}

\subsection{Quantitative metrics}

$>$ Percentage of phone calls answered or the answer \%: It works by the following formula i.e. Number of phone calls answered / Total number of phone calls. It is usually observed that at the most $60-70 \%$ of the phone calls are answered.

$>$ Booking percentage : It works by the formula: Number of of new patients booked over the phone / Total number of new patient phone calls. Most 
clinics book less than $60 \%$ of potential new patients over the phone.

$>$ Utilization \% rate : It works by the Formula: number of appointments booked / Total number of appointments on schedule. For example, a clinic manager might be interested in whether $80 \%$ of the therapist's booking schedule full? If not, is it a new patient problem or is it a patient engagement problem? Also other issues such as enough availability to fit in new patients or requirement of hiring new physiotherapist.

$>$ Graduation \% : It works by the formula : Number of patients graduated from treatment plan / total number of patients seen. One of the top struggles clinicians face with patients is getting them to commit to their care plan and see it through. In fact, only $40 \%$ or less of patients graduate from their treatment plans. Ideally it should be at least $80 \%$ by being your patients most trusted health advisor and aiming to consistently deliver complete care which promotes greater adherence.

$>$ Patient satisfaction score : It works by the formula : NPS $=(\%$ of Promoters $)-(\%$ of Detractors). Developed by Fred Reichheld, the Net Promoter System (NPS) measures the loyalty that exists between your patients and your clinic. The NPS divides your patients into three categories:

--Promoters (score 9-10): Loyal enthusiasts who will keep coming to your clinic and refer others.

--Passives (score 7 -8): Satisfied but not enthusiastic patients who are susceptible to competitive offers. Passives only count towards the total number of respondents and does not directly affect the score.

--Detractors (score 0 - 6): Unhappy patients who can damage your brand through negative word of mouth and bad reviews.

$>$ Patient handoff : It works by the formula : Patient handoff $\%=$ number of new patients walked to the front desk / total number of new patients . Small, trivial actions such as taking care of your patients , treating them like your grandparents usually improve your patient compliance and get them to stick to their treatment plans.

\subsection{Tracking Referrals metrics 3, 4}

One of the biggest sources of business for any physical therapist is from referrals. In fact, the majority of clinics depend on them as their 'bread and butter' patients that they know they will always have to build upon. You need to know who is sending the most clients over to your practice. Are other physicians directing patients to you? Are people reading online reviews? You are wise to keep track of the total referrals, top referrers, and insurance companies sending patients over. It is important to ask every new patient where they heard about you so that you can accurately monitor referral sources for your clinic. In addition to tracking the sources of your referrals you should also take the time to monitor the total number of referrals each month, who your top referrer is from month to month and even the reasons for the referrals. Major tracking referrals metrics include :

\author{
$>$ Total referrals \\ $>$ Top referrer \\ $>$ Referrals by insurance type
}

\subsection{Productivity Metrics}

In any business, one of the factors that is going to make it or break it is productivity. Clinics can also assess the efficacy of their physical therapists by analyzing metrics surrounding the average number of visits per case. It is fairly easy to monitor the productivity of staff simply by checking how many patients are seen each week in the clinic and how many each physiotherapist sees in that period. In addition to these, other productivity metrics include number of new patients coming in during certain advertising campaigns or promotions in order to determine how effective they are. Major productivity metrics include :

$>$ Patient arrival rate / average number of patient visit : It quite depends positively on the offerings and services you provide to your customers and whether your customers like them. The key to growing any healthcare business is the acquisition of new patients and the retention of established patients. The retention of the established patient is called PVA (patient visit average). Knowing PVA helps in identifying low performers and gives an indication of further training and work experience for them . This includes sub metrics such as average visit per case

$>$ Total number of new patients : There's no doubt that running a successful practice and treating patients at the same time is a balancing act. If the above mentioned metrics can be successfully implemented, it can be seen that patients numbers increases. This metric also includes sub metrics such as total number of new patients seen per location ; total number of new patients seen per therapist; average new patients per therapist ; average number patient visit per therapist ; average number of new patients visits/ revisits per therapist.

\subsection{Billing Metrics}

It is important to look at your revenue cycle and there are a number of metrics that you need to track in order to do that. Tracking the total charges that have been billed is going to help you to forecast your income and gives you better charge and command to handle your financial concerns . It is also wise to track the average charges per visit and per patient as these metrics are useful in forecasting, budgeting and even looking at pricing structures. When you examine the collected data, you can easily track the areas needed repair . Major billing metric includes:

- Total charges billed : What you don't measure you can't manage. So, knowing your most basic financial numbers or benchmarks is always going to drive a more successful private practice. Total charges billed shows you how much your clinic is billing, which comes in handy for forecasting. If you're implementing many of the leading metrics outlined above, you should automatically see your revenue numbers increase. And, your leading metrics will help you make key decisions that drive your business in a positive direction. This includes 
sub metrics such as Average charges per visit and Average charges per therapist .

\subsection{Quality indicators or quality measurement metrics 5:}

Quality indicators (QIs) are tools that are used to measure health care processes, organizational structures, and outcomes that relate to aspects of high-quality care of patients. Apart from these, physical therapists can use QIs to guide clinical decision making, implement guideline recommendations, and evaluate and report treatment effectiveness to key stakeholders, including third-party payers and patients. They can also be use by rehabilitation managers and senior decision makers to assess care gaps and achievement of benchmarks as well as to guide quality improvement initiatives and strategic planning. In 2001, the Institute of Medicine identified 6 national health care quality reporting categories that represent high-quality health care: safety, timeliness, effectiveness, efficiency, equity, and patient centeredness. Apart from these the basic quality indicators defined by them includes the assessment and monitoring of gaps related to the structures (eg. rehabilitation provider staffing levels, availability of equipment), processes (eg. adherence to rehabilitation best practices, delivery of services), or outcomes (eg. functional status, quality of life, mortality) of care.

\section{INTERPRETIVE STRUCTURAL MODELLING METHODOLOGY}

Proposed by Warfield [5], ISM methodology is a technique for establishing inter-relationships amongst the criteria of interest. This is done via a number of steps that are described as follows :

The process begins with the identification of relevant elements and thereafter establishing contextual relationship amongst them . after that the structural self - interaction matrix is created using the VAXO concept which is then followed by the creation of initial reachability matrix . final reachability matrix is then created after correcting the initial reachability matrix for any possibility of transitivity . From the reachability matrix, the reachability set and antecedent set for each criterion is found [5]. Then the intersection of these sets is derived for all elements. The element for which the reachability and intersection sets are the same is the top-level element. Then the reachability matrix is converted into the canonical matrix format by arranging the elements according to their levels. Based on the relative driving power and dependence power, factors are classified in various categories like autonomous, dependent, driver and linkage. Finally a diagraph is constructed from the canonical matrix .

\section{DEVELOPMENT OF ISM MODEL:CASE EXAMPLE FOR PHYSIOTHERAPY CLINICS}

In this section we will develop the ISM model for the various metrics related to performance of psychiatric clinics. Out of the total variables, we consider the 12 important metrics viz. percentage of phone calls answered(PPCA); Booking percentage (BP); Utilization rate (UR); graduation percentage (GP); patient handoff $(\mathrm{PH})$; total number of referrals (TNR); patient arrival (PAR); Total number of patients (TNP); total charges billed (TCB); availability of equipment (AoE); Delivery of service (DoS) and Functional status (FS) to further study the inter-relationship amongst them .

\subsection{Construction of Structural Self Interaction Matrix}

This matrix gives the pairwise relationship between two variables i.e. $i$ and $j$ based on VAXO. In this section we will develop the ISM model for the various metrics related to performance of psychiatric clinics. Out of the total variables, we consider the 12 important metrics viz. percentage of phone calls answered(PPCA); Booking percentage (BP); Utilization rate (UR); graduation percentage (GP); patient handoff $(\mathrm{PH})$; total number of referrals (TNR); patient arrival (PAR); Total number of patients (TNP); total charges billed (TCB); availability of equipment (AoE); Delivery of service (DoS) and Quality of life (QL) to further study the interrelationship amongst them .

Explanation : Utilization rate is the total number of appointments on schedule / total number of appointments booked . Number of referrals lead to utilization rate . Graduation percentage may lead to booking percentage in case patient is satisfied with the treatment. So patient handoff $\%$ may be caused by graduation percentage (Patients leaving clinic) positively. On the onset, number of referrals lead to patient handoff . Number of appointments schedule lead to patient handoff $\%$. Booking percentage lead to patient handoff $\%$. Utilization rate lead to patient handoff $\%$. Higher the phone calls answered the higher the patient handoff percentage. Booking percentage lead to patient handoff $\%$. Phone calls lead to patient handoff percentage. Positive GP may lead to new patients coming in and thereby utilization rate . PPCA as well as BP may lead to UR. GP may contribute to total number of referrals . Patient arrival rate may contribute to total number of patients. Patients leaving clinic i.e graduation patients also contribute to total number of patients. So patient handoff $\%$ may lead to graduation percentage positively . On the onset, number of referrals lead to patient handoff. Number of appointments schedule lead to patient handoff $\%$. Utilization rate lead to patient handoff $\%$. Higher the phone calls answered the higher the patient handoff percentage booking percentage lead to patient handoff $\%$. Phone calls lead to patient handoff percentage . Delivery of services re positively related to total number of patients , phone calls received, availability of equipment , patient arrival rate, total number of patients . availability of equipment may be related to total charges billed. Utilization rate lead to total number of patients . Number of referrals also contribute may be indirectly to total number of patients . Patient arrival rate depends on total number of appoints on schedule or total number of appointments booked. So it is positively related to utilization rate . PPCA .......TNP contribute to increase in bill amount and hence more revenue. More revenue may lead to satisfactory delivery of service as well as availability of equipment in clinic at the time of service. Graduation percentage may lead to better quality of life after treatment . further delivery of service also affects quality of life in the similar way. Better quality of life generates more referrals by word of mouth which in turn affects PPCA....QL. Clinic may make the equipment available based on booking percentage, total number of new patients, percentage of call answered etc. Positive and effective delivery will generate more referrals, more patients, better graduation percentage etc.

2.2.6 Email open Rate (EOR) : Email open rate helps in tracking the number of people actually opens and read the emails you send. Consistent tracking of EOR therefore can help keeping the social marketing campaigns on target. 
2.2.7 Click-through Rate (CTR): Your click-through rate tells you how appealing a particular email offer is by revealing the percentage of folks who were compelled to take action.

2.2.8 Proposals out (PO): Is your program leading prospects to requests for proposals? What does the overall pipeline look like ? Monitor this conversion by tracking the number of proposals and their dollar value.

2.2.9 Proposal wins (PO) : it determines the number of wins your marketing proposal achieve. This includes the weekly and monthly tracking of new client proposals versus existing client proposals. Apart from these the weekly or monthly number and cumulative dollar value are common win rate metrics.

2.2.10 Revenue/Sales goals (R/SG): While not exactly a measure of your firm's marketing success, revenue or sales goals should be the cornerstone of your firm's marketing plan and strategy. Related to this is the dollar volume of work sold. Only $71 \%$ of all firms track the dollar volume of work sold and only $33 \%$ share this information with marketing staff.

2.2.11 New/repeat client Ratio (N/RCR): Being able to know who you are selling to the most gives you the ability to tweak your marketing strategies to optimize for specific goals.

2.2.12 Proposal hit Rate (PHR): Fast-growth firms submitted 53\% more proposals than the average firm. Total number of contacts in the CRM database or contact mailing list. How many people receive your marketing messages? Quality is critical, but volume is important too.

2.2.13 Website Analytics (WA)/ Social media statistics (SMS) : All the statistics relating to your website. According to Zweig Group's 2016 Marketing Survey, the average number of unique visits per week in this industry is only around 750. Know your website bounce rate and average length of a page visit. Statistics such as followers, engagement, and overall impressions. This is one area where constant growth is possible. Take some time to understand your current social media presence. Then set goals and achieve them.

2.2.14 Qualified leads (QL): Qualified leads via each marketing channel and leads that result in jobs. While this can be hard to measure, do your best, then spend money on the things that are bringing in the most money.

\section{INTERPRETIVE STRUCTURAL MODELLING METHODOLOGY}

Interpretive structural modelling methodology or ISM [8] is a known technique to map the relationships amongst the relevant elements as per decision maker's problems in a hierarchical manner. Starting with the identification of elements, it proceeds with establishing the contextual relationships between elements (by examining them in pairs ) and move on towards developing the structural selfinteraction (SSIM) matrix using VAXO [8] and then initial reachability matrix and final reachability matrix and rearranging the elements in topological order using the level partition matrices. A Mic-Mac analysis is performed afterwards which categorize the variables as per the driving and dependence power in to autonomous, dependent, driver and linkage category. Finally, a diagraph can be obtained.

\section{CASE EXAMPLE}

In this section we will develop the ISM model for the various metrics related to performance of psychiatric clinics. Out of the total variables, we consider the 12 important metrics viz. percentage of phone calls answered(PPCA); Booking percentage (BP); Utilization rate (UR); graduation percentage (GP); patient handoff (PH); total number of referrals (TNR); patient arrival (PAR); Total number of patients (TNP); total charges billed (TCB); availability of equipment (AoE); Delivery of service (DoS) and Quality of life (QL) to further study the inter-relationship amongst them

\subsection{Structural self- interaction matrix (SSIM)}

This matrix gives the pairwise relationship between two variables i.e. $i$ and $j$ based on VAXO.

Explanation : Utilization rate is the total number of appointments on schedule / total number of appointments booked. Number of referrals lead to utilization rate . Graduation percentage may lead to booking percentage in case patient is satisfied with the treatment. So patient handoff $\%$ may be caused by graduation percentage (Patients leaving clinic) positively. On the onset, number of referrals lead to patient handoff . Number of appointments schedule lead to patient handoff $\%$. Booking percentage lead to patient handoff $\%$. Utilization rate lead to patient handoff $\%$. Higher the phone calls answered the higher the patient handoff percentage. Booking percentage lead to patient handoff $\%$. Phone calls lead to patient handoff percentage. Positive GP may lead to new patients coming in and thereby utilization rate . PPCA as well as BP may lead to UR. GP may contribute to total number of referrals . Patient arrival rate may contribute to total number of patients. Patients leaving clinic i.e graduation patients also contribute to total number of patients . So patient handoff $\%$ may lead to graduation percentage positively .

On the onset, number of referrals lead to patient handoff. Number of appointments schedule lead to patient handoff $\%$. Utilization rate lead to patient handoff $\%$. Higher the phone calls answered the higher the patient handoff percentage booking percentage lead to patient handoff $\%$. Phone calls lead to patient handoff percentage . Delivery of services re positively related to total number of patients , phone calls received, availability of equipment, patient arrival rate, total number of patients . availability of equipment may be related to total charges billed. Utilization rate lead to total number of patients . Number of referrals also contribute may be indirectly to total number of patients . Patient arrival rate depends on total number of appoints on schedule or total number of appointments booked . so it is positively related to utilization rate. PPCA ........TNP contribute to increase in bill amount and hence more revenue . more revenue may lead to satisfactory delivery of service as well as availability of equipment in clinic at the time of service . Graduation percentage may lead to better quality of life after treatment . further delivery of service also affects quality of life in the similar way. Better quality of life generates more referrals by word of mouth which in turn affects PPCA....QL. Clinic may make the equipment available based on booking percentage, total number of new patients , percentage of call answered etc. Positive and effective delivery will generate more referrals, more patients, better graduation percentage etc. 


\begin{tabular}{|c|c|c|c|c|c|c|c|c|c|c|c|c|c|}
\hline & & 1 & 2 & 3 & 4 & 5 & 6 & 7 & 8 & 9 & 10 & 11 & 12 \\
\hline & & PPCA & BP & UR & GP & PH & TNR & PAR & TNP & TCB & AoE & DoS & QL \\
\hline 1 & PPCA & & $\mathrm{V}$ & $\mathrm{V}$ & A & $\mathrm{V}$ & A & $\mathrm{V}$ & $\mathrm{V}$ & $\mathrm{V}$ & $\mathrm{V}$ & A & A \\
\hline 2 & BP & & & V & A & $\mathrm{V}$ & A & V & $\mathrm{V}$ & V & $\mathrm{V}$ & A & $\mathrm{A}$ \\
\hline 3 & UR & & & & A & V & $\mathrm{A}$ & V & V & V & $\mathrm{V}$ & $\mathrm{A}$ & $\mathrm{A}$ \\
\hline 4 & GP & & & & & V & V & V & V & V & $\mathrm{V}$ & A & $\mathrm{V}$ \\
\hline 5 & $\mathrm{PH}$ & & & & & & $\mathrm{A}$ & $\mathrm{V}$ & V & $\mathrm{V}$ & $\mathrm{V}$ & $\mathrm{A}$ & $\mathrm{A}$ \\
\hline 6 & TNR & & & & & & & V & V & V & V & $\mathrm{A}$ & A \\
\hline 7 & PAR & & & & & & & & $\mathrm{V}$ & $\mathrm{V}$ & $\mathrm{V}$ & $\mathrm{A}$ & A \\
\hline 8 & TNP & & & & & & & & & $\mathrm{V}$ & $\mathrm{V}$ & $\mathrm{A}$ & A \\
\hline 9 & TCB & & & & & & & & & & V & V & A \\
\hline 10 & AoE & & & & & & & & & & & V & $\mathrm{A}$ \\
\hline 11 & DoS & & & & & & & & & & & & $\mathrm{V}$ \\
\hline 12 & QL & & & & & & & & & & & & \\
\hline
\end{tabular}

Fig 1: SSIM matrix for pair wise relationship amongst barriers

\begin{tabular}{|c|c|c|c|c|c|c|c|c|c|c|c|c|c|}
\hline & & 1 & 2 & 3 & 4 & 5 & 6 & 7 & 8 & 9 & 10 & 11 & 12 \\
\hline & & PPCA & BP & UR & GP & PH & TNR & PAR & TNP & TCB & AoE & DoS & $\mathrm{QL}$ \\
\hline 1 & PPCA & 1 & 1 & 1 & 0 & 1 & 0 & 1 & 1 & 1 & 1 & 0 & 0 \\
\hline 2 & $\mathrm{BP}$ & 0 & 1 & 1 & 0 & 1 & 0 & 1 & 1 & 1 & 1 & 0 & 0 \\
\hline 3 & UR & 0 & 0 & 1 & 0 & 1 & 0 & 1 & 1 & 1 & 1 & 0 & 0 \\
\hline 4 & GP & 1 & 1 & 1 & 1 & 1 & 1 & 1 & 1 & 1 & 1 & 0 & 1 \\
\hline 5 & $\mathrm{PH}$ & 0 & 0 & 0 & 0 & 1 & 0 & 1 & 1 & 1 & 1 & 0 & 0 \\
\hline 6 & TNR & 1 & 1 & 1 & 0 & 1 & 1 & 1 & 1 & 1 & 1 & 0 & 0 \\
\hline 7 & PAR & 0 & 0 & 0 & 0 & 0 & 0 & 1 & 1 & 1 & 1 & 0 & 0 \\
\hline 8 & TNP & 0 & 0 & 0 & 0 & 0 & 0 & 0 & 1 & 1 & 1 & 0 & 0 \\
\hline 9 & TCB & 0 & 0 & 0 & 0 & 0 & 0 & 0 & 0 & 1 & 1 & 1 & 0 \\
\hline 10 & $\mathrm{AoE}$ & 0 & 0 & 0 & 0 & 0 & 0 & 0 & 0 & 0 & 1 & 1 & 0 \\
\hline 11 & DoS & 1 & 1 & 1 & 1 & 1 & 1 & 1 & 1 & 0 & 0 & 1 & 1 \\
\hline 12 & FS & 1 & 1 & 0 & 0 & 1 & 1 & 1 & 1 & 1 & 1 & 0 & 1 \\
\hline
\end{tabular}

Fig 2: Initial reachability matrix

\begin{tabular}{|c|c|c|c|c|c|c|c|c|c|c|c|c|c|c|}
\hline & & 1 & 2 & 3 & 4 & 5 & 6 & 7 & 8 & 9 & 10 & 11 & 12 & DP \\
\hline & & PPCA & BP & UR & GP & PH & TNR & PAR & TNP & TCB & AoE & DoS & QL & \\
\hline 1 & PPCA & 1 & 1 & 1 & 0 & 1 & 0 & 1 & 1 & 1 & 1 & 1 & 0 & 9 \\
\hline 2 & BP & 0 & 1 & 1 & 0 & 1 & 0 & 1 & 1 & 1 & 1 & 1 & 0 & 9 \\
\hline 3 & UR & 0 & 0 & 1 & 0 & 1 & 0 & 1 & 1 & 1 & 1 & 1 & 0 & 7 \\
\hline 4 & GP & 1 & 1 & 1 & 1 & 1 & 1 & 1 & 1 & 1 & 1 & 1 & 1 & 12 \\
\hline 5 & PH & 0 & 0 & 0 & 0 & 1 & 0 & 1 & 1 & 1 & 1 & 1 & 0 & 6 \\
\hline 6 & TNR & 1 & 1 & 1 & 0 & 1 & 1 & 1 & 1 & 1 & 1 & 1 & 0 & 10 \\
\hline 7 & PAR & 0 & 0 & 0 & 0 & 0 & 0 & 1 & 1 & 1 & 1 & 1 & 0 & 5 \\
\hline
\end{tabular}




\begin{tabular}{|c|c|c|c|c|c|c|c|c|c|c|c|c|c|c|}
\hline 8 & TNP & 0 & 0 & 0 & 0 & 0 & 0 & 0 & 1 & 1 & 1 & 1 & 0 & 4 \\
\hline 9 & TCB & 1 & 1 & 1 & 1 & 1 & 1 & 1 & 1 & 1 & 1 & 1 & 1 & 12 \\
\hline 10 & AoE & 1 & 1 & 1 & 1 & 1 & 1 & 1 & 1 & 0 & 1 & 1 & 1 & 11 \\
\hline 11 & DoS & 1 & 1 & 1 & 1 & 1 & 1 & 1 & 1 & 1 & 1 & 1 & 1 & 12 \\
\hline 12 & QL & 1 & 1 & 1 & 0 & 1 & 1 & 1 & 1 & 1 & 1 & 1 & 1 & 10 \\
\hline DeP & & 7 & 8 & 9 & 4 & 10 & 6 & 11 & 12 & 11 & 12 & 12 & 5 & \\
\hline
\end{tabular}

Fig 3 : Final reachability matrix

D.P : Driving power ; De.P : dependence power

\subsection{Level Partition}

From the final reachability matrix, reachability and final antecedent set for each factor are found. The element for which the reachability and intersection sets are same are the top-level element in the ISM hierarchy. After the identification of top level element, it is separated out from the other elements and the process continues for next level of elements. Reachability set, antecedent set, intersection set along with different level for elements have been shown below in table 4.3.1 to table 4.3.9.

Table 4.3.1: Iteration I

\begin{tabular}{|c|c|c|c|c|}
\hline $\begin{array}{l}\text { S. } \\
\text { No } \\
\text {. }\end{array}$ & $\begin{array}{c}\text { Reachability } \\
\text { set }\end{array}$ & Antecedent set & $\begin{array}{c}\text { Intersec } \\
\text { tion set }\end{array}$ & Level \\
\hline 1. & $8,10,11$ & $\begin{array}{c}1,2,3,4,5,6,7,8,9 \\
10,11,12\end{array}$ & $8,10,11$ & \multirow{9}{*}{ I } \\
\hline 2. & $7,8,9,10,11$ & $\begin{array}{c}1,2,3,4,5,6,7,9,11 \\
, 12\end{array}$ & $7,9,11$ & \\
\hline 3. & $5,7,8,9,10,11$ & $\begin{array}{c}1,2,3,4,5,6,9,11,1 \\
2\end{array}$ & $5,9,11$ & \\
\hline 4. & $\begin{array}{c}3,5,7,8,9,10 \\
11\end{array}$ & $\begin{array}{c}1,2,3,4,6,9,11 \\
12\end{array}$ & $3,9,11$ & \\
\hline 5. & $\begin{array}{c}2,3,5,7,8,9,10 \\
11\end{array}$ & $1,2,4,6,9,11,12$ & $2,9,11$ & \\
\hline 6. & $\begin{array}{c}1,2,3,5,7,8,9,1 \\
0,11\end{array}$ & $1,4,6,9,11,12$ & $1,9,11$ & \\
\hline 7. & $\begin{array}{c}1,2,3,5,6,7,8,9 \\
10,11\end{array}$ & $4,6,9,12$ & 6,9 & \\
\hline 8. & $\begin{array}{c}1,2,3,5,6,7,8,9 \\
10,11,12\end{array}$ & $4,9,12$ & 9,12 & \\
\hline 9. & $\begin{array}{c}1,2,3,4,5,6,7,8 \\
9,10,11,12\end{array}$ & 4,9 & 4,9 & \\
\hline
\end{tabular}

Table 4.3.2: Iteration II

\begin{tabular}{|c|c|c|c|c|}
\hline $\begin{array}{c}\text { S. } \\
\text { No. }\end{array}$ & $\begin{array}{c}\text { Reachability } \\
\text { set }\end{array}$ & Antecedent set & $\begin{array}{c}\text { Intersectio } \\
\text { n set }\end{array}$ & $\begin{array}{c}\text { Lev } \\
\text { el }\end{array}$ \\
\hline 2. & $\mathbf{7 , 9}$ & $1,2,3,4,5,6,7,9,12$ & $\mathbf{7 , 9}$ & \\
\hline 3. & $5,7,9$ & $1,2,3,4,5,6,9,12$ & 5,9 & \\
\cline { 1 - 4 } & $3,5,7,9$ & $1,2,3,4,6,9,12$ & 3,9 & \\
\cline { 1 - 3 } 5. & $2,3,5,7,9$ & $1,2,4,6,9,12$ & 2,9 & \\
\hline
\end{tabular}

\begin{tabular}{|c|c|c|c|c|}
\hline 6. & $1,2,3,5,7,9$ & $1,4,6,9,12$ & 1,9 & II \\
\hline 7. & $1,2,3,5,6,7,9$ & $4,6,9,12$ & 6,9 & \\
\hline 8. & $\begin{array}{c}1,2,3,5,6,7,9,1 \\
2\end{array}$ & $4,9,12$ & 9,12 & \\
\cline { 1 - 3 } 9. & $\begin{array}{c}1,2,3,4,5,6,7,9, \\
12\end{array}$ & 4,9 & 4,9 & \\
\hline
\end{tabular}

Table 4.3.3: Iteration III

\begin{tabular}{|c|c|c|c|c|}
\hline S. No. & $\begin{array}{c}\text { Reachabili } \\
\text { ty set }\end{array}$ & Antecedent set & $\begin{array}{c}\text { Intersec } \\
\text { tion set }\end{array}$ & Level \\
\hline 3. & 5 & $1,2,3,4,5,6,12$ & 5 & \multirow{7}{*}{ III } \\
\hline 4. & 3,5 & $1,2,3,4,6,12$ & 3 & \\
\hline 5. & $2,3,5$ & $1,2,4,6,12$ & 2 & \\
\hline 6. & $1,2,3,5$ & $1,4,6,12$ & 1 & \\
\hline 7. & $1,2,3,5,6$ & $4,6,12$ & 6 & \\
\hline 8. & $\begin{array}{c}1,2,3,5,6 \\
12\end{array}$ & $4,9,12$ & 12 & \\
\hline 9. & $\begin{array}{c}1,2,3,4,5,6 \\
12\end{array}$ & 4,9 & 4 & \\
\hline
\end{tabular}

Table 4.3.4: Iteration IV

\begin{tabular}{|c|c|c|c|c|}
\hline S.No. & $\begin{array}{l}\text { Reachabili } \\
\text { ty set }\end{array}$ & Antecedent set & $\begin{array}{c}\text { Intersec } \\
\text { tion set }\end{array}$ & Level \\
\hline 4. & 3 & $1,2,3,4,6,12$ & 3 & \multirow{6}{*}{ IV } \\
\hline 5. & 2,3 & $1,2,4,6,12$ & 2 & \\
\hline 6. & $1,2,3$ & $1,4,6,12$ & 1 & \\
\hline 7. & $1,2,3,6$ & $4,6,12$ & 6 & \\
\hline 8. & $1,2,3,6,12$ & $4,9,12$ & 12 & \\
\hline 9. & $\begin{array}{c}1,2,3,4,6,1 \\
2\end{array}$ & 4,9 & 4 & \\
\hline
\end{tabular}

Table 4.3.5: Iteration $\mathrm{V}$

\begin{tabular}{|c|c|c|c|c|}
\hline $\begin{array}{c}\text { S. } \\
\text { No. }\end{array}$ & $\begin{array}{c}\text { Reachability } \\
\text { set }\end{array}$ & $\begin{array}{c}\text { Antecedent } \\
\text { set }\end{array}$ & $\begin{array}{c}\text { Intersectio } \\
\text { n set }\end{array}$ & Level \\
\hline 5. & $\mathbf{2}$ & $1,2,4,6,12$ & $\mathbf{2}$ & \\
\hline 6. & 1,2 & $1,4,6,12$ & 1 & \\
\hline
\end{tabular}




\begin{tabular}{|c|c|c|c|c|}
\hline 7. & $1,2,6$ & $4,6,12$ & 6 & \multirow{2}{*}{$\mathbf{V}$} \\
\cline { 1 - 3 } 8. & $1,2,6,12$ & 4,12 & 12 & \\
\cline { 1 - 3 } 9 & $1,2,4,6,12$ & 4 & 4 & \\
\hline
\end{tabular}

Table 4.3.6: Iteration VI

\begin{tabular}{|c|c|c|c|c|}
\hline $\begin{array}{c}\text { S. } \\
\text { No. }\end{array}$ & $\begin{array}{c}\text { Reachability } \\
\text { set }\end{array}$ & $\begin{array}{c}\text { Antecedent } \\
\text { set }\end{array}$ & $\begin{array}{c}\text { Intersection } \\
\text { set }\end{array}$ & Level \\
\hline 6. & $\mathbf{1}$ & $1,4,6,12$ & $\mathbf{1}$ & \\
\cline { 1 - 4 }. & 1,6 & $4,6,12$ & 6 & \multirow{2}{*}{ VI } \\
\cline { 1 - 3 } 8 & $1,6,12$ & 4,12 & 12 & \\
\hline 9. & $1,4,6,12$ & 4 & 4 & \\
\hline
\end{tabular}

Table 4.3.7: Iteration VII

\begin{tabular}{|c|c|c|c|c|}
\hline S.No. & $\begin{array}{c}\text { Reachabili } \\
\text { ty set }\end{array}$ & Antecedent set & $\begin{array}{c}\text { Intersec } \\
\text { tion set }\end{array}$ & Level \\
\hline 7. & $\mathbf{6}$ & $4,6,12$ & $\mathbf{6}$ & \\
\hline 8. & $1,6,12$ & 4,12 & 12 & \multirow{2}{*}{ VII } \\
\hline 9. & $1,4,6,12$ & 4 & 4 & \\
\hline
\end{tabular}

Table 4.3.8: Iteration VIII

\begin{tabular}{|c|c|c|c|c|}
\hline S.No. & $\begin{array}{c}\text { Reachabili } \\
\text { ty set }\end{array}$ & Antecedent set & $\begin{array}{c}\text { Intersec } \\
\text { tion set }\end{array}$ & Level \\
\hline 8. & $\mathbf{1 2}$ & 4,12 & 12 & \multirow{2}{*}{ VIII } \\
\hline 9. & 4,12 & 4 & 4 & \\
\hline
\end{tabular}

Table 4.3.9: Iteration IX

\begin{tabular}{|c|c|c|c|c|}
\hline S.No. & $\begin{array}{c}\text { Reachabili } \\
\text { ty set }\end{array}$ & Antecedent set & $\begin{array}{c}\text { Intersec } \\
\text { tion set }\end{array}$ & Level \\
\hline 9. & 4 & 4 & 4 & IX \\
\hline
\end{tabular}

\subsection{Driving power - Dependence Diagram}

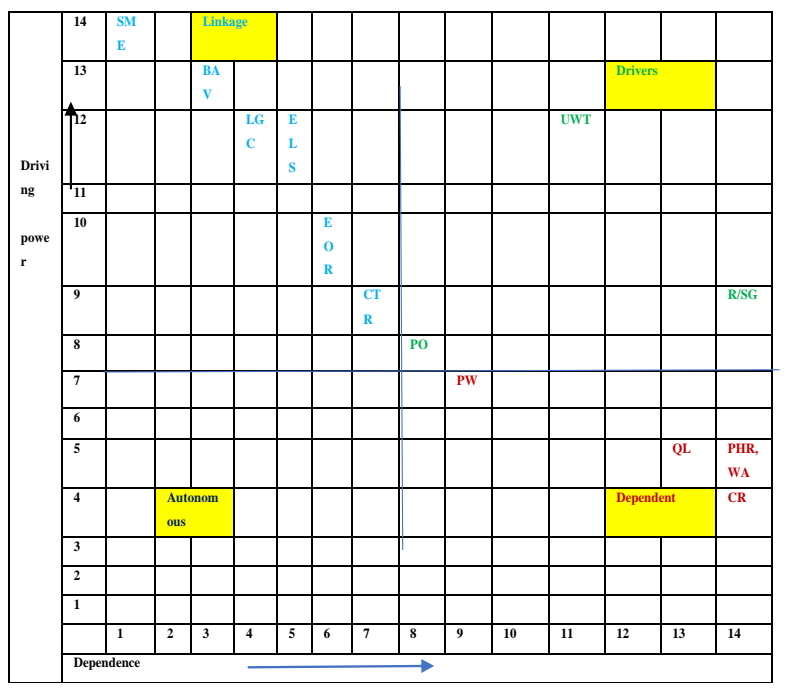

\subsection{ISM Diagraph}

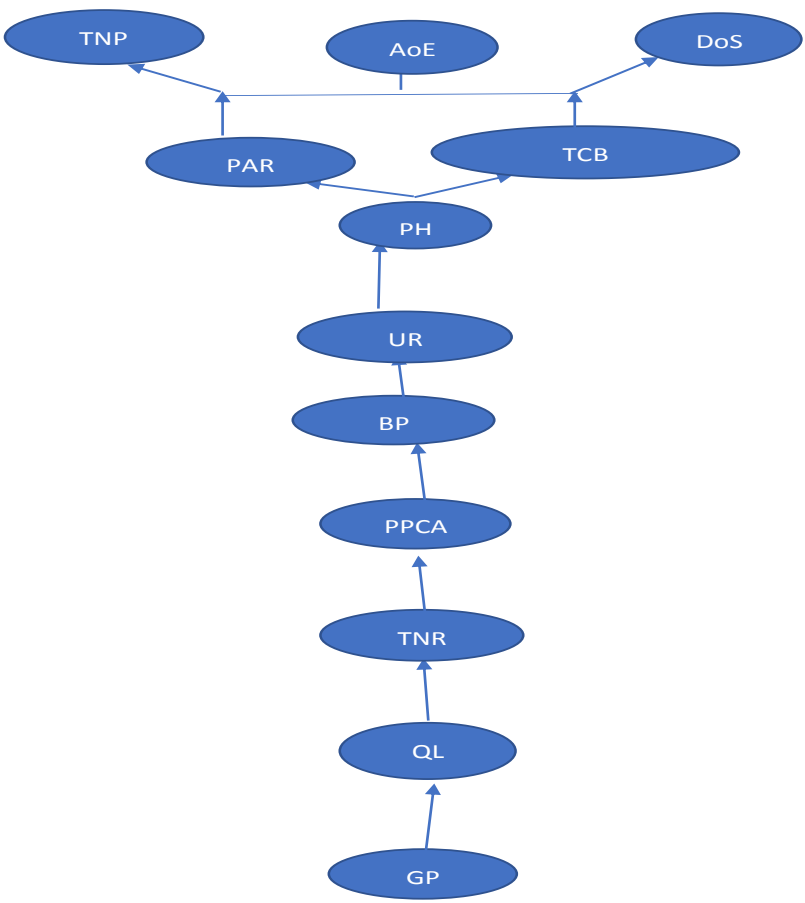

Fig : ISM Diagraph

\section{FINDINGS AND CONCLUSIONS}

The article presents an exploratory study in finding the basic metrics to assess the performance of physiotherapy or physical therapy clinics. The metrics are classified into quantitative, referral, quality measurement, billing metrics, productivity metrics and tracking referral metrics. It has been examined by the authors that little attention has been paid to the development and definition of metrics for performance evaluation of patients and clinics related to physiotherapy field. This article therefore reviews some of the reported metrics in the literature. The study has wide scope to be expanded further, some of which has been hinted in managerial implications and recommendations section.

- First, health care payers and providers will need a portfolio of validated measures of patient- centered outcomes across a spectrum of conditions commonly experienced, as well as for special populations, including children/youth.

- Secondly, health systems need to provide investment, leadership and coordination to improve and link data sources in order to measure quality across settings. Systems will need to involve frontline providers and consumers in quality measurement endorsement and design measures that fit the needs of these providers and consumers rather than those of the administrators.

- $\quad$ Thirdly, health care systems need a valid way to stratify quality measures, in order to address potential gaps among subpopulations and identify groups in most need of quality improvement.

- Fourthly, strategies for quality improvement and accountability need to be adapted, developed, and applied routinely in mental health settings. Too often systematic quality outcome measurement is driven by a desire to inform policy or reduce expenditure rather than improve treatment decisions for individuals. 
- Fifthly, quality measures need to be used in health systems that can generate near- real time data on quality in order to promote continuous quality improvement, and need to be monitored for unintentional consequences such as gaming.

- Sixthly, the presented metrics in this article can be used for evaluation of human motions in other application domains or also for assessment of sequential data in other fields, if applicable.

- Seventhly, use of Interpretive Structural Modelling , DEMATEL , Fuzzy techniques to establish the hierarchical relationships amongst the various metrics and to study the further prioritisation of these metrics based on established judgement criteria

- $\quad$ Eigthly, in some cases, health plans may be using quality and value measures to systematically monitor care delivered by the providers in their networks and to inform and monitor quality improvement and cost reduction efforts.

- Ninthly, quality indicators can be used to identify care gaps, inform health care policy and health service delivery, support accountability, promote transparency in health care, and prioritize quality improvement initiatives.

\section{ACKNOWLEDGEMENTS}

Co-Author Remica Aggarwal is thankful to Prof. S.P Singh for imparting the knowledge on ISM methodology which has helped the author substantially in preparing this manuscript . All the authors are thankful to the staff of Physiotherapy centre, Jaslok Hospital for the hospitality and care

\section{REFERENCES}

[1] Aleksandar Vakanski, Jake M. Ferguson and Stephen Lee . 2017. Metrics for Performance Evaluation of Patient Exercises during Physical Therapy. Int J Phys Med Rehabil. , 5(3): 403. doi: 10.4172/23299096.1000403

[2] Marie D. Westby, Alexandria Klemm, Linda C. , Li, C. Allyson Jones . 2016 . Emerging Role of Quality Indicators in Physical Therapist Practice and Health Service Delivery, Physical Therapy, 96(1) , 90-100 https://doi.org/10.2522/ptj.20150106.

[3] Addington, D., McKenzie, E., Addington, J., Patten, S., Smith, H., and Adair, C. 2005. Performance Measures for Early Psychosis Treatment Services, Psychiatric Services, 56(12), 1570-1582.

[4] Garland, A. F., Kruse, M., and Aarons, G. A. 2003. Clinicians and Outcome Measurement: What's the Use? The Journal of Behavioral Health Services \& Research, 30(4), 393-405.

[5] Warfield, J.N. 1974. Developing interconnection matrices in structural modelling, in the proceedings of IEEE Transactions on System, Man, and Cybernetics, SMC, 4 (1), 81-87. 